\title{
SOCIALIZAÇÃO ORGANIZACIONAL DE EXPATRIADOS
}

\author{
Gisele Costa Rabello ${ }^{1}$, Janaina Macke \& William Zanella \\ IMED Business School, Passo Fundo, Rio Grande do Sul, (Brasil)
}

\section{DETALHES DO ARTIGO}

\section{Histórico do Artigo:}

Recebido: 26 de julho de 2018

Aceito: 03 de dezembro de 2018

Disponível online: 01 de janeiro de 2019

Sistema de revisão "Double blind review"

Editor Científico

Ilan Avrichir

\section{Palavras-chaves:}

Socialização organizacional

Expatriação

Internacionalização de empresas

\begin{abstract}
RESUMO
A gestão internacional de pessoas engloba a expatriação que consiste na transferência de empregados entre as unidades da organização em diferentes países por período determinado. Para que os resultados da expatriação sejam atingidos, um processo importante é o ajustamento, que compreende a adaptação ao novo contexto. Um dos fatores de influência do ajustamento no país é a socialização organizacional, compreendida como a integração dos empregados com a organização. O objetivo dessa pesquisa foi de analisar a relação entre as táticas organizacionais e o processo de socialização organizacional de expatriados. Por meio de abordagem quantitativa e cunho descritivo, a coleta de dados ocorreu por meio de questionário online. A amostra constituiu-se por expatriados que trabalham em empresas internacionais. Os resultados foram analisados através de estatística descritiva e regressão linear. Demonstrou-se que as empresas utilizam táticas institucionalizadas para ajustar os expatriados. Identificou-se que $14 \%$ do processo de socialização organizacional é explicado pelas táticas, sendo que o impacto maior dessas táticas é percebido na dimensão da tarefa, ou seja, no papel que o expatriado irá desempenhar. A quantidade de vezes que o expatriado realizou missões internacionais pode alterar a percepção das táticas utilizadas para seu ajustamento, sendo este um achado importante desta pesquisa.
\end{abstract}

C 2018 Internext | ESPM. Todos os direitos reservados!

\section{INTRODUÇÃO}

O aumento da internacionalização de empresas pode acarretar a necessidade de transferir empregados para desempenhar atividades em outros contextos, proporcionando às pessoas experiências em diferentes aspectos profissionais. Essas experiências incluem trabalho à distância, com a utilização de diferentes tecnologias, trabalho parttime e trabalhos temporários, o que leva à mudança das políticas das empresas (Cascio, 1998). Dessa forma, verifica-se a importância da adaptação dos empregados às diferentes realidades encontradas nas empresas (Cooper-Thomas \& Anderson, 2005; Jokinen et al., 2008).

Frente a isso, a partir dos anos 90 cresceu a demanda por estudos sobre gestão internacional de recursos humanos e, com isso, surgiu a necessidade de mapear e avaliar como as empresas estão se comportando nesse novo cenário, constituído por um grupo denominado de expatriados (Haslberger et al., 2013).

Entende-se por expatriados, os empregados que são encaminhados para trabalhar e morar fora do país da matriz da empresa, desempenhando, no exterior, funções profissionais por um tempo determinado (Caligiuri, 2000; Chang et al., 2012; Mezias \& Scandura, 2005; Richardson \& Mallon, 2005; Tharenou \& Caulfield, 2010).

No entanto, devido ao alto custo inerente à manutenção de empregados expatriados, há significativa pressão por parte das empresas para gerenciá-los da melhor forma possível, implicando o

\footnotetext{
${ }^{1}$ Contato do autor - E-mail: gisele.rabello@hotmail.com
} 
ajustamento adequado ao novo contexto organizacional e ao novo ambiente cultural (Haslberger et al., 2013).

No Brasil, o tema da expatriação possui estudos ainda recentes e pouco abrangentes, o que sugere a necessidade de aprofundamento, principalmente em pesquisas que envolvam a socialização no contexto do trabalho (Homem \& Tolfo, 2008; Luiz et al., 2012). A socialização organizacional, por sua vez, é compreendida como o processo pelo qual um membro da organização recebe as informações necessárias, adquirindo o conhecimento social e as habilidades para assumir um papel específico na organização (Maanen \& Schein, 1979). Neste contexto, as táticas de socialização organizacional são definidas como a forma que a empresa estrutura para integrar e adaptar o empregado e são estruturadas em dois eixos (institucionalizadas e individualizadas) de acordo com o contexto, conteúdo e aspectos sociais pelos quais os novos empregados se submeterão ao longo do processo de socialização (Jones, 1986).

A mobilidade dos empregados tornou a questão da socialização um desafio às empresas (Feldman, 1997), por isso, é relevante identificar como as empresas internacionais têm socializado seus empregados (Perrot et al., 2014), no processo de expatriação - acentuando-se a relevância da produção acadêmica com esse tema (Ashfort \& Saks, 1996). Estes estudos concentram-se, em grande parte, na socialização organizacional de americanos em empresas internacionais, bem como em pesquisas sobre socialização de militares das Forças Armadas dos Estados Unidos (Baker III \& Feldman, 1990; Cooper-Thomas \& Anderson, 2005; Haueter et al., 2003; Kim et al., 2005) não tendo sido identificados na busca realizada para a presente pesquisa, estudos profícuos acerca de expatriados, razão que ratifica a pertinência do presente trabalho.

Enquanto no âmbito brasileiro, não se logrou identificar pesquisas dessa temática, estudos nos Estados Unidos (SRHM, 2011), ainda no ano de 2010, já apontavam que $81 \%$ das empresas afirmavam ter programas formais e informais de socialização para novos empregados. Destes, 32\% iniciam no primeiro dia de trabalho do novo empregado e os conteúdos dos programas são específicos para apresentar a organização como um todo e, a seguir, fornece-se informações do cargo que será ocupado (SHRM, 2011).
Embora o número de pesquisas sobre socialização organizacional tenha aumentado no meio acadêmico, algumas situações como as mudanças de funções, transição de carreira, entre elas, a expatriação, não tem sido observada por essa lente, ou seja, a socialização deve abranger os empregados que realizam movimento pela empresa no contexto internacional (Feldman, 1997; Fu et al., 2008).

No que se refere ao processo de socialização dos novos empregados, em geral, estes devem compreender, além de informações relativas ao contexto global da organização - como história, política e valores - a forma como é organizado o seu grupo e sua função para obter sucesso no trabalho (Haueter et al., 2003), ou seja, passar por algum processo de socialização tanto da organização, quanto do grupo ou da tarefa (Takeuchi, Wang, Marinova \& Yao, 2009).

Embora a literatura sobre a socialização organizacional aborde de maneira específica a entrada de novos empregados na empresa que não possuíam vínculo com a organização (Haueter et al., 2003), considera-se importante avaliar como a socialização organizacional está relacionada à expatriação, pois esse processo é definido como a passagem de uma barreira para outra na carreira do indivíduo (Maanen \& Schein, 1979).

O objetivo geral dessa pesquisa é analisar a relação entre as táticas de socialização e o processo de socialização organizacional de expatriados das empresas internacionais.

E como objetivos específicos: (a) identificar as características pessoais e elementos do contexto dos expatriados; (b) mensurar as táticas de socialização comumente adotadas nas empresas para o processo de socialização organizacional dos expatriados; (c) identificar o processo de socialização organizacional utilizado pelas empresas para os expatriados nas seguintes dimensões: organização, grupo e tarefa e (d) analisar as táticas de socialização no processo de socialização organizacional, nas seguintes dimensões: organização, grupo e tarefa.

Esta pesquisa contribuirá para a teoria no que tange à compreensão sobre como as empresas socializam os empregados através do uso de táticas de socialização (Perrot et al., 2014), acrescentando a isso as dimensões do processo de socialização organizacional (Takeuchi et al., 2009) em um contexto de expatriação (Fu et al., 2008). 


\section{DESENVOLVIMENTO}

\section{Expatriação}

A expatriação pode ser compreendida como estratégia organizacional para obter desenvolvimento, gerenciamento e difundir o conhecimento da matriz para as subsidiárias e entre todas as unidades, a fim de garantir aumento da rentabilidade e de mercado e também os serviços aos clientes (Beaverstock, 2004).

Selmer (2002) destaca que o executivo expatriado tem de desempenhar as funções em um contexto de trabalho desconhecido, além de encontrar um modo de vida diferente do que leva no país de origem. Para o autor, os expatriados não respondem somente os problemas de motivação, liderança e produtividade na missão internacional, mas também possuem muitas outras responsabilidades diferentes das que tinham em seu trabalho anterior quando exercido no país de origem. Ainda, o empregado expatriado não irá simplesmente trabalhar em um local que não seja a matriz: essa mudança acaba representando uma nova situação de emprego, embora seja o mesmo empregador ao qual está sendo atribuída a nova função (Mezias \& Scandura, 2005).

Durante o processo de expatriação, os empregados passam por etapas de socialização organizacional e aculturação que interferem na identidade de suas carreiras, pois Ihes é imposto, de certa forma, a necessidade de pensar e aprender novas formas, tanto no contexto cultural quanto no da tarefa (Mezias \& Scandura, 2005).

Conforme os estudos foram evoluindo, Black e Mendenhall (1991), desenvolveram a teoria mais aceita (Bhaskar-Shrinivas, Harrison \& Shaffer, 2005), segundo a qual o ajustamento ocorre em quatro fases. Na primeira fase, os empregados são encantados pela novidade que a nova cultura do país. Após, há um pico de frustração definido como um estado de choque cultural pois o empregado terá que gerenciar as mudanças no dia a dia.

A terceira fase inicia, novamente, uma adaptação gradual às novidades encontradas e o empregado irá aprender como lidar com as regras do novo país. Por fim, a quarta etapa abrange uma fase de ajustamento, na qual o empregado passa aceitar e compreender melhor o novo ambiente onde está inserido. Essa última etapa pode durar de 2 meses (Black \& Mendenhall, 1991) a 4 anos (Bhaskarshrinivas et al., 2005).
Além disso, o ajustamento é proposto por Black, Mendenhall e Oddou (1991) em duas fases: (a) antecipatório e (b) ajustamento no país anfitrião. Entre vários achados, os autores ressaltam a importância de o ajustamento internacional considerar as táticas de socialização organizacional, especialmente na dimensão do 'conteúdo' (Black; Mendenhall; Oddou, 1991). As táticas de socialização organizacional estão presentes no segundo tipo de ajustamento. Os autores propõem que táticas institucionalizadas estão associadas a um baixo grau de inovação de papel e táticas individualizadas com alto grau de inovação e, ainda, que o conteúdo que os novos empregados aprendem têm relação com essas associações na mesma proporção (Black et al., 1991).

Fu et al. (2008) realizaram um estudo sobre as táticas de socialização e o ajustamento de expatriados e identificaram ser pertinente utilizar as táticas para esse contexto. Com uma população de professores de inglês, o objetivo do estudo é compreender a socialização dentro da organização de maneira geral e específica do grupo. Os resultados do estudo mostraram que táticas institucionalizadas de socialização predizem o ajustamento no grupo e na organização.

\section{Socialização organizacional}

A socialização organizacional pode ser compreendida como um processo de ensino/aprendizagem de um novo empregado dentro de uma organização. A socialização transforma um empregado que está fora dela em um empregado vinculado a ela. Esse processo permite a ele adquirir conhecimento social e habilidades necessárias para que possa assumir determinado papel organizacional. Assim, a socialização organizacional tem como objetivo facilitar o ajustamento dos novos empregados à empresa (Ashfort \& Saks, 1996; Bauer, Bodner, Erdogan, Truxillo, \& Tucker, 2007; CooperThomas \& Anderson, 2005; Louis, 1980; Maanen \& Schein, 1979). A socialização organizacional pode ser dividida em três dimensões: organizacional, grupo e tarefa. A socialização na organização ocorre quando é transmitido ao empregado os valores e políticas da empresa (Ostroff; Kozlowski, 1992). A socialização no grupo é definida quando o empregado aprende sobre as normas e objetivos do grupo em que trabalhará (Feldman, 1981) e a presença de um mentor facilita essa socialização (Korte \& Lin, 2012). A socialização na tarefa é definida como a aquisição de informações 
sobre a atividade que será desenvolvida em uma determinada função (Major, Kozlowski, Chao, \& Gardner, 1995).

As táticas de socialização organizacional são definidas como a forma pela qual o empregado transmite seu conhecimento e experiência de determinado papel para outros empregados da organização, a fim de facilitar seu ajustamento (Baker III \& Feldman, 1990; Maanen, 1978; Maanen \& Schein, 1979). Essas táticas devem ser escolhidas de maneira consciente pela direção da organização e englobam atividades como sessões formais de treinamento e programas de orientação de função para que estejam aptos a assumirem seus papéis. Ou, também, de maneira inconsciente, sendo que os papéis devem ser aprendidos e executados por conta do próprio novo empregado. De qualquer forma, as táticas representam um conjunto de eventos que irão influenciar o novo empregado durante o processo de socialização e poderão ter respostas individuais inovadoras, bem como respostas de manutenção do papel e vice-versa (Maanen \& Schein, 1979).

Van Maanen e Schein (1979) sugerem identificar que tipo de táticas estão sendo utilizadas nas empresas, a fim de explorar os resultados das táticas sobre os empregados. Esses autores estavam interessados nos resultados da socialização, ou seja, em como ela ocorre quando os empregados mudam de posição, função e de barreiras de inclusão. Por outro lado, pesquisas empíricas abordam que tanto práticas formais ou informais são consideradas um importante fator para facilitar o processo de ajustamento (Selvarajah, 2009). As táticas de socialização foram identificadas a partir de observações empíricas e da literatura da área de ciências sociais e são definidas como: (a) Coletiva $x$ Individual; (b) Formal x Informal; (c) Sequencial $x$ Aleatória; (d) Fixa x Variável; (e) Serial x Disjuntiva; (f) Investidura x Despojamento (Maanen \& Schein, 1979).

A tática coletiva é entendida como implementar a união dos novos empregados em um determinado grupo e oferecer momentos e atividades que proporcionem a troca de experiências.

Os exemplos mais comuns desse tipo de táticas são as capacitações que envolvem um determinado departamento dentro da organização, por exemplo, treinamento de vendas (Ashforth et al., 1997; Maanen \& Schein, 1979).
A tática individual compreende a relação entre 0 novo empregado e o agente que está socializando. Ao contrário das táticas coletivas, as individuais têm um custo financeiro e de tempo extremamente alto para a organização (Maanen \& Schein, 1979).

As táticas formal e informal de socialização estão intimamente relacionadas com as táticas coletiva e individual, mas não podem ser igualadas. Essas duas primeiras táticas mencionadas no tópico anterior (coletiva $\mathrm{x}$ individual) podem ser ao mesmo tempo formal ou informal (Maanen \& Schein, 1979).

A tática formal consiste na separação do novo empregado dos empregados que já trabalham na organização por tempo determinado, a fim de proporcionar um conjunto de experiências específicas. Essa forma de socialização geralmente é identificada em empresas que necessitam preparar um novo status, além de ser importante para que o novo empregado aprenda de maneira correta as atitudes e os valores do novo papel (Ashforth et al., 1997; Maanen \& Schein, 1979).

A tática informal consiste na aprendizagem das funções a partir de tentativas e erros, de maneira mais liberal. Nessa tática não há uma distinção do novo empregado dos demais empregados da organização, sendo que os novos podem escolher quem será o agente que fará sua socialização. Diferentemente da tática formal, os erros que ocorrem nas empresas que utilizam essa tática são mais onerosos, devendo os novos membros questionarem a respeito de situações que são novas e devem ocorrer de forma correta (Maanen \& Schein, 1979).

A tática de socialização organizacional sequencial consiste na sequência de etapas que preparam o novo empregado para o novo papel. Todas as etapas desse processo de socialização são de certa forma harmoniosas e conectadas de modo lógico (Ashforth et al., 1997; Maanen \& Schein, 1979).

Na tática aleatória não há uma sequência definida das etapas que preparem o novo empregado para o novo papel, podendo às vezes ser caracterizada como ambígua, além de mudar de maneira contínua (Maanen \& Schein, 1979). As táticas fixa e variável se referem ao grau em que as etapas do processo de socialização ocorrem em um determinado período de tempo. A tática fixa proporciona ao novo empregado uma determinada precisão de tempo que será necessário para realizar a passagem de um estágio 
para outro. Por outro lado, a tática variável proporciona ao novo empregado poucas informações de quando ocorrerá o novo estágio, gerando um desconhecimento do período de passagem de um estágio ao outro. Processos de socialização variáveis podem gerar ansiedade e certos tipos de frustração aos novos empregados, pois esses são incapazes de identificar o tempo em que ocorrerão as mudanças de estágios dentro da organização (Ashforth et al., 1997; Maanen \& Schein, 1979)

A tática serial consiste em proporcionar aos novos empregados habilidades e competências semelhantes aos demais. Entretanto, essas táticas podem ocasionar ao novo empregado uma certa estagnação dentro do processo de socialização (Ashforth et al., 1997; Maanen \& Schein, 1979).

Já na tática disjuntiva não há um padrão que estabeleça a maneira como determinada tarefa deverá ser realizada no novo papel a esses novos empregados, gerando, assim, situações extremamente difíceis e também, ansiedade. Mesmo assim, a tática disjuntiva pode proporcionar ao novo empregado orientação para a inovação (Maanen \& Schein, 1979).

As táticas investidura e despojamento são definidas como a maneira pela qual a organização verifica se a identidade do novo membro pode ser confirmada ou não no processo de socialização. A tática investidura baseia-se na aceitação das características pessoais que o empregado traz de fora para dentro da organização e pode ser caracterizada como a entrada segura e tranquila do empregado para a organização (Ashforth et al., 1997; Maanen \& Schein, 1979). A tática despojamento impõe ao novo empregado a negação de suas características pessoais, sendo submetido a seguir regras rígidas dentro da organização (Maanen \& Schein, 1979).

Com isso, as táticas de socialização foram separadas em táticas institucionalizadas e táticas individualizadas (Jones, 1986). As chamadas institucionalizadas constituem programas estruturados de socialização e proporcionam aos novos empregados a aceitação de forma passiva das regras estabelecidas, reforçando o status quo. Contrário a isso, as táticas individualizadas não são organizadas de maneira estruturada e proporcionam aos novos empregados avaliar e desafiar o status quo e desenvolver suas próprias visões sobre as regras (Ashforth et al., 1997; Jones, 1986).
Jones (1986) argumenta que as seis táticas de socialização organizacional têm três focos diferentes. Primeiro, coletiva (versus individual) e formal (versus informal) compõe o 'contexto' pelo que cada organização fornece informações aos seus novos empregados. Em segundo lugar, sequencial (versus aleatória) e fixa (versus variável) pertencem principalmente ao 'conteúdo' da informação fornecida pela socialização, onde os estágios/etapas são específicos em uma ordem fixa (sequencial) com cronogramas já estabelecidos (fixa). Por último, serial (versus disjuntiva) e investidura (versus despojamento) compõem os 'aspectos sociais' da socialização, pois implicam diretamente outros membros da organização (Jones, 1986).

No estudo realizado por Baker III e Feldman (1990), as táticas investidura/despojamento apresentaram maior impacto na socialização. Ainda, as táticas sequencial, fixa e serial demonstraram um impacto moderado. Já as táticas formal/informal e coletiva/individualizada tiverem o menor impacto nos novos membros.

As táticas de socialização institucionalizadas são positivamente associadas ao ajustamento na organização e no grupo, sendo que está positivamente relacionado ao comprometimento organizacional e à performance na função (Bauer et al., 2007; Fu et al., 2008).

\section{MÉTODO}

A presente pesquisa classifica-se como estudo descritivo, com abordagem quantitativa e delineamento transversal.

A população contemplou-se os empregados de empresas internacionais que estão expatriados e também aqueles que já o foram. A amostra considerou os empregados expatriados de empresas internacionais selecionadas por conveniência (Malhotra, 2006). A coleta de dados foi feita por meio de questionário eletrônico composto por duas partes, a primeira em aferições sobre táticas de socialização e processo de socialização; e, a segunda, pela caracterização da amostra. Na primeira parte, constam as questões sobre as táticas de socialização adaptadas do questionário de Jones (1986). A versão original do questionário era dividida em seis dimensões e um total de 30 questões, reduzidas a 18 para este estudo. Ao final das questões de cada dimensão, foi incluída uma questão geral, a fim de medi-la na sua totalidade, averiguando a 
concordância/discordância geral da dimensão. Ainda na primeira parte, as perguntas sobre o processo de socialização foram adaptadas de Haueter et al. (2003). A proposta original do autor identificou as diferentes dimensões da socialização organizacional (organização, grupo e tarefa) e foi composto por 35 questões. No entanto, para a presente pesquisa, reduziu-se para 9 questões e, no final de cada dimensão, foi elaborada uma questão geral a fim de medi-la na sua totalidade.

Para as questões das táticas de socialização e das dimensões da socialização, foram utilizadas escalas Likert expandida em 7 pontos e foram utilizadas questões abertas e fechadas.

Os questionários originais foram adaptados para a língua portuguesa e também passou por tradução reversa.

A validação do questionário foi realizada por três especialistas da área acadêmica e por um profissional de recursos humanos. Após essa validação, efetuouse um pré-teste com dois profissionais de empresas internacionais que já estiveram expatriados.

O questionário foi formatado no Qualtrics e enviado o link do questionário, por meio de rede social Facebook, Linkedin ou e-mail. Para essa etapa, utilizou-se a técnica bola de neve, que possibilita ao indivíduo repassar o instrumento de coleta a outras pessoas (Malhotra, 2006).

Durante o período da coleta dos dados, 126 participantes iniciaram o questionário online. Contudo, 40 participantes não terminaram de preenchê-lo, o que implica 32\% de desistência. Assim, foram totalizados 86 questionários completamente preenchidos e válidos. Desconsiderando 6 questionários de expatriados que não são de nacionalidade brasileira foram utilizados 80 questionários para a análise dos dados. Destes 80 respondentes, 49 estão atualmente expatriados e 31 já passaram pelo processo de expatriação (repatriados).

As técnicas de análise de dados utilizadas abrangem a estatística descritiva e a regressão linear simples e múltipla. Inicialmente, os missing values foram excluídos da análise, pois algumas das variáveis apresentaram valor superior a $10 \%$ de respostas faltantes (Malhotra, 2006).

Para análise dos dados utilizou-se a estatística descritiva, considerando as variáveis: frequência, média, desvio padrão e variância. Para análise de confiabilidade foi analisada pelo Alpha de Cronbach, sendo que o limite inferior geralmente aceito é de 0,70 (Hair et al., 2009). Também, foram utilizadas regressão linear simples, coeficiente $r 2$ (coeficiente de determinação), e regressão linear múltipla.

\section{ANÁLISE E DISCUSSÃO DOS RESULTADOS}

A análise estatística indica que a confiabilidade interna dos construtos, escalas das táticas de socialização $(\alpha=0,855)$ e escala da socialização organizacional ( $\alpha=0,858)$, é aceita, sendo que $\alpha=0,70$ é o valor de referência (HAIR et al., 2009), demonstrando que aproximadamente $90 \%$ das respostas são confiáveis.

Esses dados corroboram com as pesquisas realizadas por Jones (1986), Kim, Cable e Kim (2005) e Perrot (2014), que encontraram para esse indicador os valores de 0,68 a 0,84; 0,89 e 0,85 para as táticas, respectivamente. Já para a escala de socialização, o estudo realizado por Haueter et al. (2003) apresentou confiabilidade interna de 0,94.

Quanto ao primeiro objetivo da pesquisa, o qual foi caracterizar a amostra da pesquisa, a maior parte da amostra foi composta por homens, com uma frequência de 76 respondentes e 4 mulheres, ou seja, $95 \%$ e $5 \%$, respectivamente.

A partir disso, a caracterização da amostra foi dividida em dois grupos: empregados que estão expatriados, denominado aqui como grupo 1 , e os repatriados, denominado grupo 2 .

No que se refere aos expatriados (grupo 1), da totalidade da amostra $(n=80), 49$ respondentes estão atualmente no processo de expatriação, ou seja, $61 \%$.

A expatriação ocorreu apenas uma vez para a maioria dos respondentes, ou seja, $71 \%(n=35)$ estão passando pelo referido processo, o que é ratificado pela pesquisa de Selvarajah (2009) que identificou que a missão internacional havia ocorrido pela primeira vez. Quanto aos demais, $18 \%(n=9)$ já foram expatriados duas vezes, $6 \%(n=3)$ três vezes, e $4 \%$ $(n=2)$ mais de três momentos da carreira.

No que se refere ao período de expatriação atual dos respondentes, observa-se a média de 41,39 meses (desvio padrão de 41,54 meses), sendo o período mínimo de 1 mês e o máximo de 180 meses, ou seja, 15 anos.

Com isso, respalda-se a literatura, a qual denomina a expatriação como tempo de transferência de um país para outro, diferente do país 
de origem, podendo variar de dois anos ou mais (Caligiuri, 2000). Considerando as etapas do ajustamento, a quarta etapa é a fase de ajustamento e dura em média 2 meses (Black; Mendenhall, 1991) a 4 anos (Bhaskar-Shrinivas; Harriso; Shaffer, 2005).

Portanto, por essa teoria, pode-se considerar que os expatriados da presente pesquisa encontram-se ajustados pois, estão em média, 3 anos no processo de expatriação. Essa etapa, conforme os autores, é caracterizada pela aceitação da nova cultura, costumes e hábitos conhecidos durante o processo. Relativamente aos empregados repatriados (grupo 2), a totalidade da amostra $(n=80)$ indica que 31 respondentes passaram, em algum momento da vida profissional, pelo processo de expatriação, ou seja, $38,8 \%$.
Quanto ao segundo objetivo específico da pesquisa, o qual era de mensurar as táticas de socialização comumente adotadas nas empresas para o processo de socialização organizacional dos expatriados, é importante ressaltar que maiores médias indicam táticas institucionalizadas e médias baixas indicam as individualizadas (Allen \& Meyer, 1990a; Ashfort \& Saks, 1996; Jones, 1986; Kim, Cable, \& Kim, 2005; Perrot et al., 2014).

Para a análise, foram consideradas as variáveis gerais de cada dimensão do questionário (Coletiva/Individual;Formal/Informal;Sequencial/Ale atória;Fixa/Variável;Serial/Disjuntiva;Investidura/Des pojamento), conforme elaborado por Maanen e Schein (1979).

Tabela 1 - Estatística descritiva das táticas de socialização por dimensão

\begin{tabular}{|c|c|c|c|c|c|c|}
\hline \multicolumn{2}{|c|}{ Construto } & Dimensão & $\mathrm{n}$ & Média & Desvio padrão & Variância \\
\hline \multirow{6}{*}{$\begin{array}{c}\text { Táticas de } \\
\text { socialização }\end{array}$} & \multirow{2}{*}{ Contexto } & $\mathrm{Col} / \mathrm{Ind}$ & 80 & 5,15 & 1,5434 & 2,38 \\
\hline & & For/Inf & 80 & 4,57 & 1,7046 & 2,90 \\
\hline & \multirow{2}{*}{ Conteúdo } & Seq/Ale & 80 & 4,83 & 1,5380 & 2,36 \\
\hline & & Fix/Var & 80 & 3,38 & 1,5870 & 2,51 \\
\hline & \multirow{2}{*}{$\begin{array}{l}\text { Aspectos } \\
\text { sociais }\end{array}$} & Ser/Dis & 80 & 4,66 & 1,8276 & 3,34 \\
\hline & & Inv/Des & 80 & 5,87 & 1,2156 & 1,47 \\
\hline
\end{tabular}

Fonte: Dados da pesquisa (2017).

É possível inferir que as médias das respostas dos expatriados (grupo 1) indicam valores mais altos, caracterizando as táticas dessa pesquisa como institucionalizadas, o que demonstra que a percepção dos expatriados quanto às formas de socialização ocorre de maneira estruturada e formal. Esses resultados confirmam os achados de Saks e Gruman (2011), bem como o estudo realizado por Burböck, Schnepf e Pessi (2016), que demonstrou a preferência de estudantes alemães, austríacos e suíços pelas táticas institucionalizadas. Outro estudo demonstrou a aplicação de táticas institucionalizadas em empresas portuguesas (Dias, 2014).

Tais táticas são definidas como atividades planejadas e sistemáticas que a empresa desenha para socializar os empregados (Kim et al., 2005). Considerando que as táticas institucionalizadas induzem os empregados a aceitarem os valores e objetivos estabelecidos pela empresa e estão diretamente relacionadas ao aumento do comprometimento do empregado (Allen \& Meyer, 1990b; Ashfort \& Saks, 1996; Griffin, Colella, \& Goparaju, 2000).

Entende-se que os expatriados da presente pesquisa aceitaram estes desafios, pois a média da duração da expatriação foi de 3,5 a 4,4 anos.

A resposta que o empregado dá à empresa quando esta utiliza táticas institucionalizadas denomina-se respostas de adesão, ou seja, baseia-se na aceitação dos papéis tradicionais (Maanen \& Schein, 1979).

Quando comparada as médias, o grupo dos empregados repatriados (grupo 2) apresentou uma diferença entre as médias, referente a quantidade de vezes que foram expatriados e a percepção das táticas, ou seja, a diferença de médias foi significativa demonstrando, que a quantidade de vezes que o expatriado realizou as missões internacionais pode alterar a percepção das táticas utilizadas para o ajustamento do empregado. 
Tabela 2 - Comparação de médias (ANOVA) das táticas de socialização

\begin{tabular}{|c|c|c|c|c|c|c|c|c|}
\hline & & & & & $\begin{array}{r}\text { Intervalo } \\
\text { de } 95 \%\end{array}$ & $\begin{array}{l}\text { de confiança } \\
\text { ara média }\end{array}$ & & \\
\hline & $\begin{array}{c}\text { Qtde de } \\
\text { vezes que } \\
\text { foi } \\
\text { expatriado }\end{array}$ & $\mathrm{N}$ & Média & $\begin{array}{l}\text { Desvio } \\
\text { padrão }\end{array}$ & $\begin{array}{l}\text { Limite } \\
\text { inferior }\end{array}$ & $\begin{array}{l}\text { Limite } \\
\text { superior }\end{array}$ & Mín & Máx \\
\hline \multirow{6}{*}{$\begin{array}{c}\text { Táticas de } \\
\text { socialização }\end{array}$} & $1 \mathrm{vez}$ & 17 & 4,71 & 1,29 & 4,04 & 5,37 & 2,83 & 6,50 \\
\hline & 2 vezes & 11 & 4,82 & 0,48 & 4,50 & 5,14 & 4,00 & 5,67 \\
\hline & 3 vezes & 1 & 1,83 & . & . & . & 1,83 & 1,83 \\
\hline & $\begin{array}{c}\text { mais de } 3 \\
\text { vezes }\end{array}$ & 2 & 3,42 & 0,35 & 0,24 & 6,59 & 3,17 & 3,67 \\
\hline & Total & 31 & 4,57 & 1,16 & 4,15 & 4,99 & 1,83 & 6,50 \\
\hline & & & & $\begin{array}{l}\text { Soma dos } \\
\text { Quadrados }\end{array}$ & $d f$ & $\begin{array}{l}\text { Quadrado } \\
\text { Médio }\end{array}$ & $\mathrm{F}$ & Sig. \\
\hline \multirow{3}{*}{$\begin{array}{c}\text { Táticas de } \\
\text { socialização }\end{array}$} & \multicolumn{2}{|l|}{ Entre Grupos } & & 11,141 & 3 & 3,714 & \multirow{3}{*}{3,456} & \multirow{3}{*}{0,03} \\
\hline & \multicolumn{2}{|l|}{ Nos grupos } & & 29,013 & 27 & 1,075 & & \\
\hline & \multicolumn{2}{|l|}{ Total } & & 40,154 & 30 & & & \\
\hline
\end{tabular}

Fonte: Dados da pesquisa (2017).

Deve-se considerar que as táticas possuem uma preocupação com o contexto, conteúdo e aspectos sociais no processo de socialização organizacional (Jones, 1986). Embora a literatura informe que no contexto internacional os aspectos sociais são os mais difíceis de gerenciar (Feldman, 1997), nessa pesquisa essa dimensão totalizou 5,26 de média, sendo o maior valor. Os aspectos sociais têm como foco principal as relações interpessoais entre o novo empregado e os responsáveis pelo processo de socialização na empresa, bem como as questões sobre feedback, reconhecimento da identidade do novo empregado, o apoio da organização (Bauer et al., 2007; Burböck et al., 2016) e, ainda, o suporte de familiares (Selvarajah, 2009). Acredita-se que isso possa ser percebido nessa pesquisa, pois na expatriação, as empresas buscam pessoas com capacidade de relacionamento, capazes de gerenciar as mais diversas situações e que se adaptem ao perfil da empresa (Pinheiro, Esteves, \& Suleman, 2015).

Tabela 3 - Estatística descritiva das táticas de socialização por dimensão

\begin{tabular}{cccccc}
\hline Construto & Dimensões* & N & Média & $\begin{array}{c}\text { Desvio } \\
\text { padrão }\end{array}$ & Variância \\
\hline \multirow{2}{*}{ Táticas de } & Contexto & 80 & 4,86 & 1,4275 & 2,03 \\
socialização & Conteúdo & 80 & 4,11 & 1,3870 & 1,92 \\
& $\begin{array}{c}\text { Aspectos } \\
\text { sociais }\end{array}$ & 80 & 5,26 & 1,3143 & 1,72 \\
\hline
\end{tabular}

Fonte: Dados da pesquisa (2017).

Quanto ao terceiro objetivo específico, o qual foi de identificar 0 processo de socialização organizacional utilizado pelas empresas para os expatriados nas seguintes dimensões: organização, grupo e tarefa, foram identificadas as médias, desvios padrões e variâncias de cada questão do questionário referentes à socialização organizacional que é dividida em três dimensões: na organização, quando é repassado ao empregado os valores, políticas e regras da empresa (Ostroff; Kozlowski, 1992); no grupo, quando o empregado aprende sobre as normas, objetivos e valores do setor ou departamento em que trabalhará (Feldman, 1981); na tarefa, definida como a aquisição de informações sobre a atividade que será desempenhada e a aprendizagem dos comportamentos necessários para desempenhar tarefas importantes, interagindo com outras pessoas durante essa tarefa (Major et al., 1995). Em que pese a percepção seja bastante semelhante nas três dimensões (organização, grupo e tarefa), observa-se que a socialização na tarefa teve a média 6,41, ou seja, a maior média. Ao contrário são os estudos de Haueter et al. (2003) e Korte e Lin (2012), que verificaram que a socialização no grupo é 
a mais percebida pelos respondentes da pesquisa. Como a expatriação tem como foco principal o desempenho de uma função específica, esse dado sugere que a socialização na tarefa realmente seja a mais relevante para esse momento da vida do empregado. Nesse sentido, convém salientar que a incerteza quanto aos objetivos, metas e função a ser desempenhada são fatores que geram estresse nos expatriados quando realizam as missões internacionais (Bhaskar-Shrinivas et al., 2005).

Tabela 4 - Estatística descritiva da socialização organizacional por dimensão

\begin{tabular}{ccccccccc}
\hline Construto & Dimensão* & N & $\begin{array}{c}\text { Mínim } \\
\text { o }\end{array}$ & Máximo & Média & $\begin{array}{c}\text { Desvio } \\
\text { padrão }\end{array}$ & Variância \\
\hline \multirow{2}{*}{ Socialização } & Organização & 80 & 1 & 7 & 6,30 & 0,99 & 0,99 \\
organizacional & Grupo & 80 & 1 & 7 & 6,21 & 0,88 & 0,77 \\
& Tarefa & 80 & 1 & 7 & 6,41 & 0,85 & 0,72 \\
\hline
\end{tabular}

Fonte: Dados da pesquisa (2017).

Quando comparada as médias, o grupo dos empregados repatriados (grupo 2) apresentou uma diferença entre as médias, referente a quantidade de vezes que foram expatriados e a percepção da socialização, ou seja, a diferença de médias foi significativa.

Tabela 5 - Comparação de médias (ANOVA) da socialização organizacional

\begin{tabular}{|c|c|c|c|c|c|c|c|c|}
\hline & $\begin{array}{c}\text { Qtde de } \\
\text { vezes que } \\
\text { foi } \\
\text { expatriado }\end{array}$ & $\mathrm{N}$ & Média & $\begin{array}{l}\text { Desvio } \\
\text { padrão }\end{array}$ & $\begin{array}{l}\text { Intervalo } \\
\text { de } 95 \% \\
\text { Limite } \\
\text { inferior }\end{array}$ & $\begin{array}{l}\text { confiança } \\
\text { ra média } \\
\text { Limite } \\
\text { superior }\end{array}$ & Mín & Máx \\
\hline \multirow{6}{*}{$\begin{array}{c}\text { Socialização } \\
\text { organizacional }\end{array}$} & $1 \mathrm{vez}$ & 17 & 6,67 & 0,35 & 6,48 & 6,85 & 6,00 & 7,00 \\
\hline & 2 vezes & 11 & 6,24 & 0,67 & 5,79 & 6,69 & 5,00 & 7,00 \\
\hline & 3 vezes & 1 & 6,00 & . & . & . & 6,00 & 6,00 \\
\hline & $\begin{array}{c}\text { mais de } 3 \\
\text { vezes }\end{array}$ & 2 & 4,33 & 1,41 & $-8,37$ & 17,04 & 3,33 & 5,33 \\
\hline & Total & 31 & 6,34 & 0,79 & 6,06 & 6,63 & 3,33 & 7,00 \\
\hline & & & $\begin{array}{l}\text { Soma dos } \\
\text { Quadrados }\end{array}$ & $d f$ & $\begin{array}{l}\text { Quadrado } \\
\text { Médio }\end{array}$ & $\mathrm{F}$ & Sig. & \\
\hline \multirow{3}{*}{$\begin{array}{c}\text { Socialização } \\
\text { organizacional }\end{array}$} & Entre Grupos & & 10,087 & 3 & 3,362 & & & \\
\hline & Nos grupos & & 8,465 & 27 & 0,314 & 10,725 & 0,00 & \\
\hline & Total & & 18,552 & 30 & & & & \\
\hline
\end{tabular}

Fonte: Dados da pesquisa (2017).

Para o quarto objetivo específico, o qual foi de analisar as táticas no processo de socialização organizacional nas seguintes dimensões: organização, grupo e tarefa, utilizou-se a regressão linear, a fim de analisar as táticas no processo de socialização, com o escopo de estabelecer a relação de significância. Analisou-se como variável independente as táticas de socialização e como dependente a socialização organizacional. Relevante mencionar que, para ser considerada significativa, deve ser menor que 0,05. Destaca-se que as táticas de socialização explicam $14 \% \quad\left(r^{2}=0,143\right) \quad d a$ socialização organizacional, conforme a variância das variáveis das táticas de socialização.

Considerando que a socialização organizacional é vista por duas perspectivas, a funcionalista e a interacionista simbólica, este estudo abrangeu somente a perspectiva funcionalista, a qual entende a socialização como um "processo de manutenção e reprodução da estrutura social ou como processo de homogeneização" (Borges; Albuquerque, 2014, p. 352). Assim, analisando os estudos da área (Ashforth et al., 1997; Baker III \& Feldman, 1990; Feldman, 1981), é importante considerar também os outros aspectos da socialização organizacional, que incluem as interações do indivíduo e suas interpretações e proatividade, ou seja, os aspectos cognitivos, ao invés das ações que a empresa realiza. Outrossim, aspectos culturais também devem ser observados para explicar a socialização, já que se trata de uma amostra de pessoas que passam a viver em outro contexto cultural e organizacional (Black et al., 1991).

Ainda, foram realizadas as análises com as dimensões da socialização como variáveis 
dependentes, sendo que uma delas demonstrou que $14 \%$ da socialização na tarefa é explicada pela variância das variáveis das táticas de socialização. Conforme verificado, a maior relação encontrada foi na socialização da tarefa. Haueter et al. (2003) explicam que treinamentos profissionais, os quais entende-se como táticas institucionalizadas, não têm um efeito significativo na socialização nas dimensões da organização e do grupo. Portanto, como identificado na presente pesquisa, houve relação com as três dimensões, porém, a mais significativa foi a dimensão da tarefa.

Embora estudos comprovem que o uso de táticas institucionalizadas tenha impacto na dimensão da socialização na organização, os achados desta pesquisa demonstram que essas variáveis explicam somente $0,8 \%$, o que se pode atribuir ao fato de que os empregados já conheciam a empresa na qual trabalhavam. $\mathrm{O}$ estudo realizado por Cooper-Thomas e Anderson (2002) demonstrou que as táticas foram preditores mais fortes das áreas de informação mais diretamente relacionadas ao trabalho do papel/tarefa $\left(r^{2}=0,17\right)$ e organização $\left(r^{2}=0,07\right)$, dados que também podem ser verificado nesta pesquisa.

Foi realizada ainda a regressão linear múltipla das dimensões das táticas (contexto, conteúdo e aspectos sociais) para identificar qual delas é mais significativa no processo da socialização organizacional. As táticas de socialização referentes ao conteúdo explicam $14 \%$ da socialização organizacional.

Em que pese as táticas de contexto e conteúdo tenham sido as menores médias, 4,86 e 4,11 respectivamente, conforme a percepção dos expatriados, são as duas dimensões que mais explicam a socialização organizacional. Considerando que as táticas de conteúdo abordam as informações específicas para o desempenho da função para a qual o empregado foi contratado, no contexto da expatriação percebe-se que os expatriados relatam que percebem mais a socialização na tarefa. Desse modo, as práticas institucionalizadas acabam diminuindo a criatividade e inovação do empregado, incentivando-o a seguir as orientações previamente prescritas pela empresa (Ashforth, et al., 2007).

O estudo de Ashforth et al. (1997) demonstra que os aspectos sociais têm mais impacto no processo de socialização, seguido da dimensão do conteúdo e, posterior a eles, em menor grau, a dimensão do contexto. Destaca-se que o apoio de colegas de trabalho na adaptação do expatriado ajuda a minimizar as incertezas geradas pela expatriação (Bhaskar-Shrinivas et al., 2005).

Assim, pode se inferir que nas táticas (sequencial e fixa) preocupam-se com o conteúdo da informação, ou seja, existe um cronograma e acompanhamento de antigos empregados para o processo de socialização (Jones, 1986), de modo que o expatriado irá desempenhar somente o que já foi estabelecido ou que é repassado pelo funcionário mais antigo, gerando a socialização na dimensão da tarefa mais evidente.

\section{CONSIDERAÇÕES FINAIS}

$\mathrm{Na}$ presente pesquisa, buscou-se como objetivo geral analisar a relação entre as táticas de socialização e o processo de socialização organizacional de expatriados das empresas internacionais. Quanto ao primeiro objetivo específico, observa-se que a amostra de expatriados foi predominantemente masculina. Ainda, confirmase que os objetivos da expatriação são a transferência de conhecimento da matriz para as demais unidades e o crescimento/desenvolvimento de carreira.

Quanto ao segundo e terceiro objetivo específico, pode-se identificar que as empresas que atuam em contexto internacional transferem seus profissionais e os socializam no novo ambiente de trabalho de forma estruturada e formal. As táticas identificadas na pesquisa se classificam como institucionalizadas, as quais possibilitam gerar um maior impacto da socialização na dimensão da tarefa que será desempenhada, a partir do auxílio e suporte de colegas de trabalho, ou seja, são focadas em aspectos sociais. E, por fim, o quarto objetivo, conclui-se que há relação das táticas no processo de socialização de expatriados, com $14 \%$ de explicação do modelo.

Considerando que a teoria da socialização organizacional aborda as diversas etapas da carreira do empregado (Maanen; Schein, 1979), observa-se que os estudos não demonstram esse tema no contexto da expatriação. Assim, identifica-se que a presente pesquisa abordou como as empresas socializam as pessoas através do uso de táticas de socialização (Perrot et al., 2014), acrescentando a isso as dimensões do processo de socialização organizacional (Takeuchi et al., 2009) em um contexto de expatriação (Fu et al. 2008). Atribui-se importância aos estudos que consigam identificar de que forma as empresas socializam os seus empregados, a fim de verificar se o que se espera do expatriado no momento de uma missão internacional 
e se táticas impostas pela empresa irão atingir o objetivo desta missão, pois sabe-se que muitas empresas não possuem programas de recursos humanos bem definidos para dar suporte aos expatriados (Webb \& Wright, 1996). Conforme verificado nas análises, a quantidade de vezes que o expatriado realizou as missões internacionais impactam na percepção das táticas de socialização. Essa variável deve ser observada no momento de elaborar políticas de socialização para o processo de expatriação. As limitações da pesquisa foram elencadas, conforme segue: (a) teve como foco somente a socialização no contexto do trabalho, embora não tivesse como objetivo analisar variáveis de aspecto cultural do país onde o expatriado esteve trabalhando, acredita-se ser relevante abordar questões deste aspecto; (b) por se tratar de um estudo transversal observa-se que seria relevante avaliar após algum tempo a socialização para verificar se há mudança na percepção; (c) o instrumento utilizado avaliou a percepção do expatriado por meio de autorelato e (d) a quantidade de respondentes.

Como implicações acadêmicas identificou-se: (a) com o levantamento bibliográfico das teorias e estudos pertinentes às temáticas chave desta pesquisa, construiu-se um instrumento no qual foi elaborada uma variável geral para medir a percepção global das dimensões das táticas de socialização e do processo de socialização organizacional; (b) o questionário na sua versão original estabeleceu pouca diferença entre as médias quando comparadas

\section{REFERÊNCIAS}

Allen, N. J., \& Meyer, J. P. (1990a). Organizational Socialization Tactics: A Longitudinal Analysis of Links to Newcomers' Commitment and Role Orientation. The Academy of Management Journal, 33(4), 847858.

Allen, N. J., \& Meyer, J. P. (1990b). Organizational Socialization Tactics: A Longitudinal Analysis of Links to Newcomers' Commitment and Role Orientation. Academy of Management Journal, 33(4), 847-859.

Ashfort, B. E., \& Saks, A. M. (1996). Socialization Tactics: Longitudinal Effects on Newcomer Adjustment. Academy of Management Journal, 39(1), 149-178.

Ashforth, B. E., Saks, A. M., \& Lee, R. T. (1997). On the Dimensionality of Jones' (1986) Measures of Organizational Socialization Tactics. International com a variável geral; (c) a pesquisa observou de que forma as táticas de socialização implicam nas dimensões da socialização; (d) essa pesquisa corrobora os principais achados na literatura, os quais demonstram que $\mathrm{o}$ uso de táticas de socialização tem algum tipo de impacto no processo de socialização organizacional e (e) os achados afirmam que a socialização no contexto do trabalho pode ser utilizada na expatriação.

Como implicações gerenciais, identificou-se: (a) poderá facilitar a elaboração de programas de socialização para os expatriados durante o momento da missão; (b) qualificar a socialização dos empregados, facilitando o atingimento dos objetivos e metas da empresa e (c) para definir um programa de socialização, deve se levar em conta, além das necessidades do empregado, a demanda da empresa para o atingimento dos objetivos alinhados à sua estratégia, observando quais foram as finalidades que motivaram a expatriação. É necessário saber que não há melhores ou piores táticas para socializar o empregado na empresa.

Como pesquisas futuras sugere-se: (a) avaliar a percepção do gestor da empresa quanto às táticas e a socialização organizacional, com abordagem qualitativa; (b) analisar de que forma as táticas utilizadas pelas empresas internacionalizadas afetam o desempenho do expatriado, avaliando o sucesso da expatriação e (c) avaliar a relação das táticas e a razão pela qual o expatriado foi enviado ao país hospedeiro, ou seja, identificar o motivo da expatriação.

Journal of Selection and Assessment, 5(4), 200-214.

Ashforth, B. E., Sluss, D. M., \& Saks, A. M. (2007). Socialization tactics, proactive behavior, and newcomer learning: Integrating socialization models. Journal of Vocational Behavior, 70(3), 447-462. https://doi.org/10.1016/j.jvb.2007.02.001

Baker III, H. E., \& Feldman, D. C. (1990). Strategies of Organizational Socialization and Their Impact on Newcomer Adjustment. Journal of Managerial Issues, 2(2), 198-212.

Bauer, T. N., Bodner, T., Erdogan, B., Truxillo, D. M., \& Tucker, J. S. (2007). Newcomer adjustment during organizational socialization: a meta-analytic review of antecedents, outcomes, and methods. Journal of Applied Psychology, 92(3), 707-721. https://doi.org/10.1037/0021-9010.92.3.707

Beaverstock, J. V. (2004). "Managing across borders": knowledge management and expatriation 
in professional service legal firms. Journal of Economic Geography, 4(2), 157-179. https://doi.org/10.1093/jeg/4.2.157

Bhaskar-shrinivas, P., Harrison, D. A., \& Shaffer, M. A. (2005). Input-Based and Time-Based Models of International Adjustment: Meta-Analytic Evidence and Theoretical Extensions. Academy of Management Journal, 48(2), 257-281.

Black, J. S., \& Mendenhall, M. (1991). The U-curve adjustment hypothesis revisited: A review and theoretical framework. Journal of International Business Studies, 11(October), 225-247.

Black, J. S., Mendenhall, M., \& Oddou, G. (1991). Toward a Comprehensive Model of International Adjustment: An Integration of Multiple Theoretical Perspectives. Academy of Management Review, 16(2), 291-317. https://doi.org/10.5465/AMR.1991.4278938

Borges, L. de O., \& Albuquerque, F. J. B. de. (2014). Socialização organizacional. In J. C. Zanelli, J. E. Borges-Andrade, \& A. V. B. Bastos (Orgs.), Psicologia, organizações e trabalho no Brasil $\left(2^{\circ}\right.$, p. 615). São Paulo: Artmed.

Burböck, B., Schnepf, S., \& Pessl, S. (2016). Individualized versus institutionalized socialisation tactics. Advances in Business-Related Scientific Research Journal, 7(1), 25-43.

Caligiuri, P. M. (2000). Selecting Expatriates for Personality Characteristics: A Moderating Effect of Personality on the Relationship Between Host National Contact and Cross-cultural Adjustment. MIR: Management International Review, 40(1), 61-80. https://doi.org/10.1017/CBO9781107415324.004

Cascio, W. F. (1998). The virtual workplace: A reality now. The Industrial-Organizational Psychologist, 35(4), 32-37.

Chang, Y., Gong, Y., \& Peng, M. W. (2012). Expatriate knowledge transfer, subsidiary absorptive capacity, and subsidiary performance. Academy of Management Journal, 55(4), 927-948. https://doi.org/http://dx.doi.org/10.5465/amj.2010. 0985

Cooper-Thomas, H., \& Anderson, N. (2002). Newcomer Adjustment: The Relationship Between Organizational Socialization Tactics, Information Acquisition and Attitudes. Journal of Occupational and Organizational Psychology, 75(4), 423-437.

Cooper-Thomas, H. D., \& Anderson, N. (2005). Organizational Socialization: A Field Study into
Socialization Success and Rate. International Journal of Selection and Assessment, 13(2), 116-128.

Dias, G. M. R. S. (2014). Socialização organizacional: A integração de novos funcionários nas organizações. Universidade Lusófona de Humanidades e Tecnologias.

Feldman, D. C. (1981). The Multiple Socialization of Organization Member. The Academy of Management Review, 6(2), 309-318.

Feldman, D. C. (1997). Socialization in an International Context. International Journal of Selection and Assessment, 5(1), 1-8.

Fu, C. K., Hsu, Y., \& Shaffer, M. A. (2008). Socialization Tactics, Fit, and Expatriate Outcomes. Academy of Management Proceedings, 1-6.

Griffin, A. E. C., Colella, A., \& Goparaju, S. (2000). Newcomer and Organizational Socialization Tactics: An Interactionist Perspective. Human Resource Management Review, 10(4), 453-474.

Hair JR., J.F.; William, B.; Babin, B.; Anderson, R. E. Análise multivariada de dados. 6.ed. Porto Alegre: Bookman, 2009.

Haslberger, A., Brewster, C., \& Hippler, T. (2013). The Dimensions of Expatriate Adjustment. Human Resource Management, 52(3), 333-351. https://doi.org/10.1002/hrm

Haueter, J. A., Macan, H., \& Winter, J. (2003). Measurement of newcomer socialization: construct validation of a multidimensional scale. Journal of Vocational Behavior, 63(1), 20-39. https://doi.org/10.1016/S0001-8791(02)00017-9

Homem, I. D., \& Tolfo, S. da R. (2008). Práticas de Gestão Internacional de Pessoas: Compensação e Seleção de Expatriados em uma Multinacional Brasileira. RAC - Eletrônica, 2(2), 201-217.

Jokinen, T., Brewster, C., \& Suutari, V. (2008). Career capital during international work experiences: contrasting self-initiated expatriate experiences and assigned expatriation. The International Journal of Human Resource Management, 19(6), 979-998. https://doi.org/10.1080/09585190802051279

Jones, G. R. (1986). Socialization tactics, selfefficacy, and newcomers' adjustments to organizations. Academy of Management Journal, 29(2), 262-279.

Kim, T., Cable, D. M., \& Kim, S.-P. (2005). Socialization Tactics, Employee Proactivity, and 
Person-Organization Fit. Journal of Applied Psychology, 90(2),

https://doi.org/10.1037/0021-9010.90.2.232

Korte, R., \& Lin, S. (2012). Getting on Board: Organizational Socialization and the Contribution of Social Capital. Human Relations, 1-22. https://doi.org/10.1177/0018726712461927

Louis, M. R. (1980). Surprise and sense making: What newcomers experience in entering unfamiliar organizational settings. Administrative science quarterly, 25(2), 226-251. https://doi.org/10.2307/2392453

Luiz, R. da C. R., Santos, I. C. dos S., \& Tadeucci, M. de S. R. (2012). A Expatriação como Estratégia de Aprendizagem Organizacional e Carreira. Revista de Carreiras e Pessoas, 2(2), 74-83.

Maanen, J. Van. (1978). People Processing: Strategies of Organizational Socialization. Organizational Dynamics, 7(1), 19-36.

Maanen, J. Van, \& Schein, E. H. (1979). Toward a Theory of Organizational Socialization. In Research in organizational behavior (p. 1-90).

MALHOTRA, N. K. Pesquisa de Marketing: Uma Orientação Aplicada. 4. ed. Porto Alegre: Bookman, 2006.

Major, D. A., Kozlowski, S. W. J., Chao, G. T., \& Gardner, P. D. (1995). A Longitudinal Investigation of Newcomer Expectations, Early Socialization Outcomes, and the Moderating Effects of Role Development Factors. Journal of Applied Psychology, 80(3), 418-431.

Mezias, J. M., \& Scandura, T. A. (2005). A NeedsDriven Approach to Expatriate Adjustment and Career Development: A Multiple Mentoring Perspective. Journal of International Business Studies, 36(5), 519-538.

Ostroff, C., \& Kozlowski, S. W. J. (1992). Organizational Socialization as a Learning Process: The Role of Information Acquisition. Personnel Psychology, 45(4), 849-875.

Perrot, S., Bauer, T. N., Abonneau, D., Campoy, E., Erdogan, B., \& Liden, R. C. (2014). Organizational socialization tactics and newcomer adjustment: The moderating role of perceived organizational support.
Group \& Organization Management, 39(3), 1-27. https://doi.org/10.1177/1059601114535469

Pinheiro, A., Esteves, T., \& Suleman, F. (2015). Seleção e Competências dos Expatriados e Estratégias de Internacionalização: Um Estudo Exploratório de Empresas Portuguesas. Revista Portuguesa e Brasileira de Gestão, 14(1), 48-60.

Richardson, J., \& Mallon, M. (2005). Career interrupted? The case of the self-directed expatriate. Journal of World Business, 40(4), 409-420. https://doi.org/10.1016/j.jwb.2005.08.008

Saks, A. M., \& Gruman, J. a. (2011). Getting newcomers engaged: the role of socialization tactics. Journal of Managerial Psychology, 26(5), 383-402. https://doi.org/10.1108/02683941111139001

Selmer, J. (2002). Practice Makes Perfect? International Experience and Expatriate Adjustment. MIR: Management International Review, 42(1), 7187.

Selvarajah, C. (2009). Organisational support during expatriation: a study of New Zealand managers. International Journal Business Excellence, 2(1), 65-85.

SHRM, S. for H. R. M. (2011). SHRM Survey Findings: Onboarding Practices Key Findings. Recuperado 11 de abril de 2016, de https://www.shrm.org/research/surveyfindings/doc uments/OnboardingPractices_FINAL.pdf

Takeuchi, R., Wang, M., Marinova, S. V., \& Yao, X. (2009). Role of Domain-Specific Facets of Perceived Organizational Support During Expatriation and Implications for Performance. Organization Science, 20(3),

621-634.

https://doi.org/10.1287/orsc.1080.0403

Tharenou, P., \& Caulfield, N. (2010). Will I stay or will I go? Explaining repatriation by self-initiated expatriates. Academy of Management Journal, 53(5), 1009-1028.

https://doi.org/10.5465/AMJ.2010.54533183

Webb, A., \& Wright, P. C. (1996). The expatriate experience: implications for career success. Career Development International, 1(5), 38-44. 


\section{SOBRE OS AUTORES}

- Gisele Costa Rabello - Mestra em Administração pela Faculdade Meridional IMED Business School, Rio Grande do Sul, (Brasil). E-mail: gisele.rabello@hotmail.com Orcid id: https://orcid.org/0000-00026441-2114

- Janaina Macke - Pós-doutorado na Université Joseph Fourier, (França). Doutora em Administração pela Universidade Federal do Rio Grande do Sul - UFRGS, Rio Grande do Sul. E-mail: jmacke@imed.edu.br Orcid id: https://orcid.org/0000-0002-7781-7161

- William Zanella - Doutor em Administração pela Universidade São Caetano do Sul - USCS, São Paulo, (Brasil). E-mail: william.zanella@gmail.com Orcid id: https://orcid.org/0000-0002-8187-9824

\section{Organizational Socialization of Expatriates}

Gisele Costa Rabello, Janaina Macke \& William Zanella

IMED Business School, Passo Fundo, Rio Grande do Sul, (Brazil)

ARTICLE DETAILS
Article history:
Received: 26 july 2018
Accepted: 03 December 2018
Available online January: 01th 2019
Double Blind Review System
Scientifc Editor
llan Avrichir

\section{Keywords:}

Organizational socialization

Expatriation

Internationalization of companies

\begin{abstract}
International human resources management encompasses expatriation consisting of the transfer of employees between the units of the organization in different countries for a specific period. To achieve the expatriation results, an important process is adjustment, which involves adapting to the new context. One of the factors influencing the adjustment in the country is the organizational socialization, understood as the integration of the individual with the organization. The aim of this research was to analyze the relationship between organizational tactics and the process of organizational socialization of expatriates. Through a quantitative approach and a descriptive character, the data collection took place in an online questionnaire. The sample consisted of expatriates working in international companies. The results were analyzed through descriptive statistics and linear regression. It was shown that companies use institutionalized tactics to adjust employees. It was identified that $14 \%$ of the process of organizational socialization is explained by the tactics, being that the greater impact of these tactics are perceived in the dimension of the task, that is, the role that the employee will act. The number of times the expatriate has performed international missions may alter the perception of the tactics used for his adjustment, which is an important finding of this research.
\end{abstract}

(C) 2018 Internext | ESPM. All rights reserved!

Para citar este artigo:

Rabello, G., Macke, J., \& Zanella, W. (2019). Socialização Organizacional de Expatriados. Revista Eletrônica de Negócios Internacionais, 14(1), 45-58. doi:https://doi.org/10.18568/internext.v14i1.461 